DOI: 10.20472/IAC.2019.048.041

\title{
TUGBA OZISIK
}

ISTANBUL KULTUR UNIVERSITY, Turkey

\section{OPINIONS AND EXPECTATIONS OF STUDENTS OF ECONOMICS IN A TURKISH UNIVERSITY}

\begin{abstract}
:
With a population of more than 80 million, Turkey has a great number of young people wishing to get a university degree and have an edge in the competition for a job. However, to what extent they have a clear idea about the department they choose is a question mark. This study focuses on the opinions of 3rd grade university students in the Department of Economics at İstanbul Kültür University. It aims to compare the motivational factors through which these students decided to study Economics with their current points of view about this field of study. It also analyzes students' career expectations and beliefs about job opportunities after graduation. In order to gather data, students were given questionnaires and a descriptive analysis was carried out. In addition, a focus group meeting with the students was organized. Common themes emerged from the transcriptions of the meeting were supported by students' actual sentences. Findings reveal that a surprising number of students have different ideas from the time they started studying Economics, both from positive to negative and negative to positive, which might suggest that during the critical phase of choosing a career path, most students are not fully aware of what is waiting for them. Moreover, almost two thirds of the students do not have high hopes of getting a decent job due to the nonstable economy and the problem of unemployment in the country.
\end{abstract}

\section{Keywords:}

Keywords: Higher Education, Student Opinions, Career Expectations.

JEL Classification: 129 